\title{
Septic rupture of the ascending aorta after aortocoronary bypass
}

\section{surgery}

\author{
Christof M Sommer*1, Tobias Heye ${ }^{1}$, Ulrike Stampfl ${ }^{1}$, Ursula Tochtermann², \\ Boris A Radeleff ${ }^{1}$, Hans U Kauczor ${ }^{1}$ and Goetz M Richter ${ }^{1}$
}

\begin{abstract}
Address: ${ }^{1}$ Department of Diagnostic and Interventional Radiology, University Hospital Heidelberg, Heidelberg, Germany and ${ }^{2}$ Department of Cardiac Surgery, University Hospital Heidelberg, Heidelberg, Germany

Email: Christof M Sommer* - christof.sommer@med.uni-heidelberg.de; Tobias Heye - tobias.heye@med.uni-heidelberg.de; Ulrike Stampfl - ulrike.stampfl@med.uni-heidelberg.de; Ursula Tochtermann - ursula.tochtermann@med.uni-heidelberg.de; Boris A Radeleff - boris.radeleff@med.uni-heidelberg.de; Hans U Kauczor - hu.kauczor@med.uni-heidelberg.de;

Goetz M Richter - goetz.richter@med.uni-heidelberg.de

* Corresponding author
\end{abstract}

Published: 16 December 2008

Journal of Cardiothoracic Surgery 2008, 3:64 doi:10.1 186/1749-8090-3-64

Received: 17 July 2008

Accepted: 16 December 2008

This article is available from: http://www.cardiothoracicsurgery.org/content/3/1/64

(C) 2008 Sommer et al; licensee BioMed Central Ltd.

This is an Open Access article distributed under the terms of the Creative Commons Attribution License (http://creativecommons.org/licenses/by/2.0), which permits unrestricted use, distribution, and reproduction in any medium, provided the original work is properly cited.

\begin{abstract}
We describe an exceptional case of non-fatal septic rupture of the ascending aorta in a patient with sternal dehiscence, deep sternal wound infection (DSWI) and pleural empyema after aortocoronary bypass surgery. Routine follow-up computed tomography (CT) detected a mediastinal pseudoaneurysm originating from the ascending aorta. Thereby, massive and irregular sternal bone defects and contrast-enhancing mediastinal soft tissue suggest osteomyelitis and highly-active and aggressive DSWI as initial triggers. Urgent thoracotomy I day later included ascending aorta reconstruction, total sternum resection and broad wound debridement. Follow-up CT I year later showed a regular postoperative result in a fully recovered patient.
\end{abstract}

\section{Background}

Sternal dehiscence is a frequent complication after aortocoronary bypass surgery with an incidence estimated at $1 \%$ to $6 \%$ in a normal population [1]. When complicated by sternum osteomyelitis and DSWI, prolonged hospitalization and increased cost of care, morbidity and mortality as high as $20 \%$ is reported [2]. Broken wire fixations and displaced bone fragments with non-physiological sternal movement seem to be essential in its pathogenesis [3]. Obesity, diabetes mellitus, chronic obstructive pulmonary disease and previous sternotomy make up the major risk factors [4]. Despite antibiotic therapy and aggressive surgical interventions, the prognosis is serious [5]. In this case report, we describe a patient developing non-fatal septic rupture of the ascending aorta with mediastinal pseudoaneurysm triggered by sternum osteomyeli- tis and extensive DSWI after aortocoronary bypass surgery.

\section{Case presentation}

A 65-year-old male white was referred to our department for routine follow-up CT for sternal dehiscence, DSWI and pleural empyema developing after aortocoronary bypass operation 9 months before. His history included congenital portal vein stricture with recurrent ascites, acute myocardial infarction 4 months ago, systemic hypertension, hypercholesteremia, renal insufficiency, penicillin allergy and methicillin-resistant staphylococcus aureus in the blood culture. Medication consisted of spironolactone, metoprolol succinate, furosemide, ramipril, acetylsalicylate, zinc aspartate and zolpidem tartrate. Physical examination was carried out in the Department of Cardiac 
Surgery right before the CT and revealed pressure-like pectoral pain and non-physiological sternal movement. Laboratory showed elevated c-reactive protein $(58 \mathrm{mg} / \mathrm{l})$, ferritin $(1450 \mu \mathrm{g} / \mathrm{l})$ and gamma-glutamyl transferase (77 $\mathrm{U} / \mathrm{l})$, whereas choline esterase $(3110 \mathrm{U} / \mathrm{l})$ and hemoglobin $(12.5 \mathrm{~g} / \mathrm{dl})$ were reduced. Electrocardiogram and tropoine $\mathrm{T}$ were unremarkable. CT detected massive sternal bone defects, inhomogenous bone matrix and irregular sternotomy edges as evidence for long-lasting chronic osteomyelitis (Figure 1). Clearly contrast-enhancing soft tissue in the upper and anterior mediastinum documeted highly-active and aggressive DSWI (Figure 2A, B). An ovalshaped massive contrast-enhancing retrosternal mass

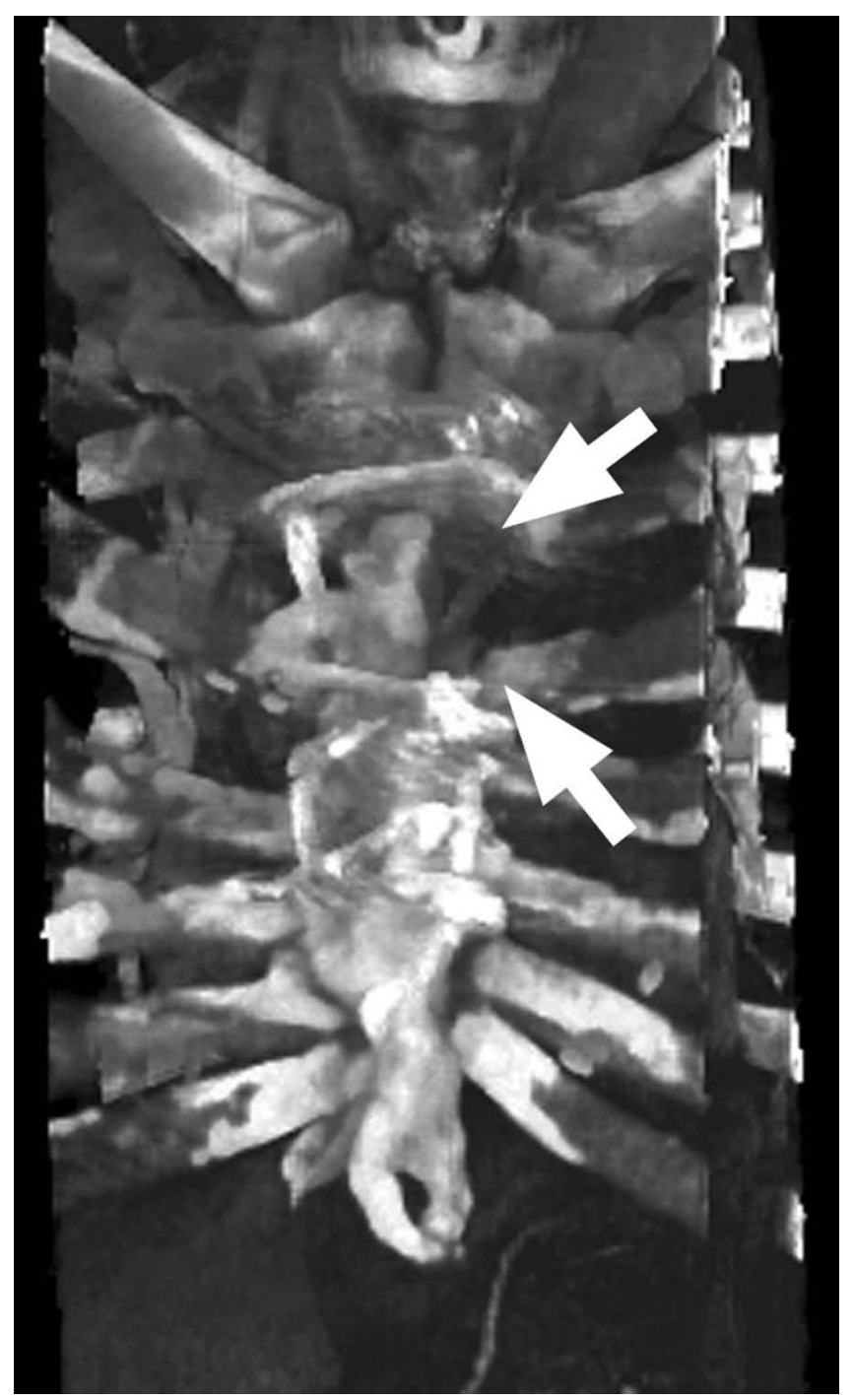

Figure I

Sternum osteomyelitis. CT 3D-reconstruction shows massive sternal bone defects, inhomogenous bone matrix and irregular sternotomy edges (white arrows) as evidence for long-lasting chronic osteomyelitis
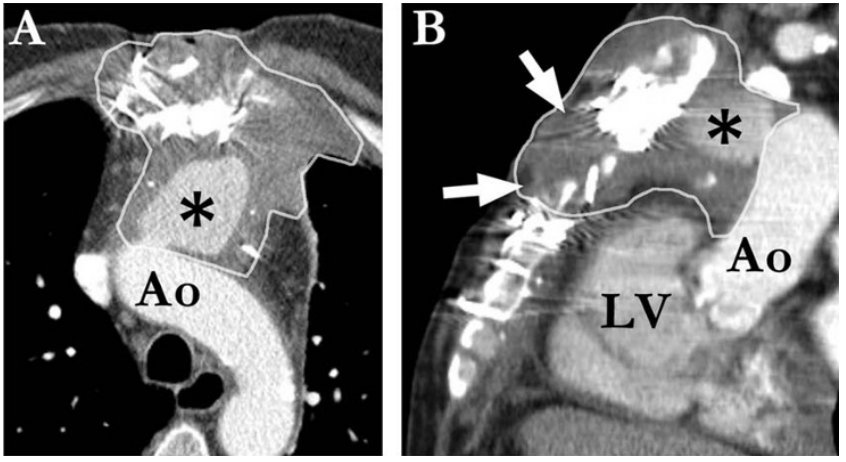

Figure 2

DSWI with pseudoaneurysm. CT axial (A) and sagittal

(B) reconstructions show clearly contrast-enhancing soft tissue in the upper and anterior mediastinum (areas encirceled by white lines); ascending aorta (Ao), pseudoaneurysm (asterisk), left ventricle (LV) and massive sternal bone defects (white arrows).

directly within the DSWI with narrow connection to the ascending aorta indicated a mediastinal pseudoaneurysm (Figure 2). Because hyperacute aortic rupture was unlikely due to postoperative mediastinal scarring, the patient underwent urgent thoracotomy 1 day later. Ascending aorta reconstruction with insertion of a pericardial patch, total sternum resection, broad wound debridement inclusive of soft tissue reconstruction with a pectoralis plastic was carried out. Intraoperative mediastinal bacterial smear tests verified existence of methicillin-resistant staphylococcus aureus. Postoperative CT 2 days later demonstrated a proper thoracic aorta. 12 days later, the patient was transferred from intensive care unit to ward. Another 8 days later, he was admitted to a peripher hospital in good clinical condition. Outpatient routine follow-up CT 1 year later documented a regular postoperative result in a fully recovered patient.

\section{Conclusion}

Midline sternotomy is by far the most common surgical approach in cardiac surgery. One disadvantage of this technique is the relatively frequent occurence of sternal dehiscence with instability [1]. It is described as nonphysiological sternal movement after disruption of wire fixations [3]. Because of its decreased blood supply, especially the lower sternal third is affected. Moreover, utilization of the internal mammary artery for coronary artery bypass grafting leads to additional and acute reduction of the sternal blood supply [6]. When this situation is complicated by infection, which occurs especially in patients with immunosuppression, sternum osteomyelitis and DSWI might develop as devastating complications despite strict sterility and antibiotic prophylaxis [7]. In case of aggressive mediastinal propagation, cardiac suture lines might be eroded with septic shock or hemorrhage as fatal 
complications [7]. It is well known, that continuous bacterial spread from or within a soft tissue compartment might cause vascular infection characterized as bacterial aortitis, infected aorta, ruptured mycotic aneurysm or spontaneous non-aneurysmal suppurative vascular rupture [8]. Sugawara et al. described a ruptured abdominal aorta secondary to klebsiella pneumonia psoas muscle abscess [9]. The typical mechanism of aortic rupture, which is expansion of an atherosclerotic aneurysm, is virtually impossible in our patient. Neither the short period of only 9 months nor pseudoaneurysm configuration directly within the DSWI support this. Much more probable is chronic septic vascular erosion resulting in aortic rupture with pseudoaneurysm formation. Aggressive surgical interventions with broad wound debridement, plastic reconstruction, bone removal and mediastinal irrigation with antiseptic solutions in combination with intravenous antibiotic therapy seem to be the only chance to control extensive sternal osteomyelitis with DSWI and to prevent even worse complications [5]. Accomplished in our patient, admission to a peripher hospital was possible in good clinical condition 22 days later and outpatient routine follow-up CT 1 year later documented a regular postoperative result in a fully recovered patient.

\section{Consent}

Written informed consent was obtained from the patient for publication of this case report and accompanying images. A copy of the written consent is available for review by the Editor-in-Chief of this journal.

\section{Competing interests}

The authors declare that they have no competing interests.

\section{Authors' contributions}

CMS conceived the study. TH prepared the figures. CMS and TH performed the CT-examination. CMS and US did the background literature search and drafted the manuscript. UT was the cardiac surgeon. BAR participated in study design and coordination. HUK and GMR were involved in the conception of the study and the critical review of the intellectual content of the manuscript. All authors have read and approved the final manuscript.

\section{References}

I. Kiessling $A H$, Isgro F, Weisse U, Moltner A, Saggau W, Boldt J: Advanced sternal closure to prevent dehiscence in obese patients. Ann Thorac Surg 2005, 80:1537-1539.

2. Hollenbeak CS, Murphy DM, Koenig S, Woodward RS, Dunagan WC, Fraser VJ: The clinical and economic impact of deep chest surgical site infections following coronary artery bypass graft surgery. Chest 2000, I I 8:397-402.

3. El-Ansary D, Waddington G, Adams R: Measurement of nonphysiological movement in sternal instability by ultrasound. Ann Thorac Surg 2007, 83:1513-1516.

4. Schimmer C, Reents W, Elert O: Primary closure of median sternotomy: a survey of all German surgical heart centers and a review of the literature concerning sternal closure technique. Thorac Cardiovasc Surg 2006, 54:408-4I3.
5. De Feo M, Renzulli A, Ismeno G, Gregorio R, Della Corte A, Utili R, Cotrufo $M$ : Variables predicting adverse outcome in patients with deep sternal wound infection. Ann Thorac Surg 200I, 7l:324-33I.

6. Di Marco RF Jr, Lee MW, Bekoe S, Grant KJ, Woelfel GF, Pellegrini RV: Interlocking figure-of-8 closure of the sternum. Ann Thorac Surg 1989, 47:927-929.

7. Toumpoulis IK, Anagnostopoulos CE, Derose JJ Jr, Swistel DG: The impact of deep sternal wound infection on long-term survival after coronary artery bypass grafting. Chest 2005, I 27:464-47I.

8. Orend $\mathrm{KH}$, Storck M, Brand R, Becker HM: Non-aneurysmal suppurative aortic rupture. Eur J Vasc Endovasc Surg 1995, I0:I| 8 -121.

9. Sugawara Y, Sato O, Miyata T, Kimura H, Yamaoka M, Uozaki H, Oka $T$, Makuuchi M: Ruptured abdominal aorta secondary to psoas muscle abscess due to Klebsiella pneumoniae in an alcoholic. J Infect 1997, 35: 185-188.

\section{Publish with BioMed Central and every scientist can read your work free of charge}

"BioMed Central will be the most significant development for disseminating the results of biomedical research in our lifetime. " Sir Paul Nurse, Cancer Research UK

Your research papers will be:

- available free of charge to the entire biomedical community

- peer reviewed and published immediately upon acceptance

- cited in PubMed and archived on PubMed Central

- yours - you keep the copyright

Submit your manuscript here:

http://www.biomedcentral.com/info/publishing_adv.asp
BioMedcentral 